\title{
Camilo Salgado e suas três faculdades de medicina
}

\author{
Camilo Salgado and his three medical colleges
}

Camilo Salgado y sus tres facultades de medicina

José Maria de Castro Abreu Junior

Instituto Histórico e Geográfico do Pará, Universidade Federal do Pará, Belém, Pará, Brasil
Aristóteles Guilliod de Miranda

Instituto Histórico e Geográfico do Pará, Universidade Federal do Pará, Belém, Pará, Brasil

\section{RESUMO}

O artigo revê a formação do médico no Brasil, na última década do século XIX, nas únicas escolas médicas então existentes (Rio de Janeiro e Bahia) tomando como base os anos acadêmicos de Camilo Salgado, que posteriormente foi figura de destaque na história da medicina no Estado do Pará.

Palavras-chave: Centros Médicos Acadêmicos; Medicina; História da Medicina; Ensino Médico; Escolas Médicas.

\section{INTRODUÇÃO}

O presente estudo teve por objetivo mostrar alguns aspectos da formação médica brasileira nos primeiros anos da República, período de grandes transformações na ciência médica mundial, nas duas únicas escolas existentes no País, situadas em Salvador, Estado da Bahia e no Rio de Janeiro, Estado do Rio de Janeiro, respectivamente, bem como as relações entre aquelas instituições. $\bigcirc$ ponto de partida é um esboço biográfico de Camilo Henriques Salgado Junior (1873-1938) enquanto estudante de medicina, e que depois de formado foi um cirurgião de prestígio na medicina paraense, destaque em grandes acontecimentos médicos e políticos do Estado do Pará e até hoje cultuado como "santo popular" na Cidade de Belém", mas, que paradoxalmente, ainda não foi tema de grandes estudos biográficos.

\section{CAMILO SALGADO - ACADÊMICO DE MEDICINA E O DIA A DIA NAS FACULDADES DA BAHIA E DO RIO DE JANEIRO NO FINAL DO SÉCULO XIX}

O País mal acabara de sair do Império e iniciar o período republicano quando o jovem Camilo Salgado ingressou no curso médico. $O$ ano era $1891^{2}$, e as opções para quem queria enveredar pelas sendas

Correspondência / Correspondence / Correspondencia:

José Maria de Castro Abreu Junior

Trav. Mauriti, 2218. Bairro: Pedreira

CEP: 66087-680 Belém-Pará-Brasil

E-mail: josemcair@yahoo.com.br da medicina sem sair do Brasil, eram apenas duas: a Faculdade de Medicina da Bahia ou a Faculdade de Medicina do Rio de Janeiro, na capital da recém-proclamada República. A terceira faculdade de medicina surgiria apenas em 1898, no Rio Grande do Sul, quando Camilo já estava formado.

Camilo, curiosamente, frequentou os dois polos de ensino médico de seu tempo, já que fez uma parte de seu curso em Salvador e a outra no Rio de Janeiro. As duas escolas seguiam um programa de seis anos, que na época não era dividido em semestres, mas em "séries de exames" contando com as seguintes disciplinas assim distribuídas:

$1^{a}$ série: Física Médica, Química Mineral e Mineralogia Médicas, Botânica e Zoologia Médicas.

$2^{a}$ série: Anatomia Descritiva, Histologia Teórica e Prática, Química Orgânica e Biológica.

$3^{a}$ série: Fisiologia Teórica e Experimental, Anatomia e Fisiologia Patológicas, Patologia Geral.

$4^{a}$ série: Patologia Médica, Patologia Cirúrgica, Matéria Médica e Terapêutica especialmente a brasileira.

$5^{a}$ série: Obstetrícia, Anatomia Cirúrgica, Medicina Operatória e Aparelhos, Farmacologia e Arte de Formular.

$6^{a}$ série: Higiene e História da Medicina, Medicina Legal e Toxicologia.

$7^{a}$ série: Clínica Médica de Adultos, Clínica Cirúrgica de Adultos, Clínica Obstétrica e Ginecológica. 
8a Série: Clínica Médica e Cirurgia de Crianças, Clínica Oftalmológica, Clínica de Moléstias Cutâneas e Sifilíticas, Clínica Psiquiátrica ${ }^{3, *}$.

Historicamente podemos considerar que ambas as escolas foram criadas juntas, em 1808, por Dom João $\mathrm{VI}$ ao chegar ao Brasil fugindo das tropas napoleônicas. A escola da Bahia é alguns meses mais antiga, graças a um incidente meteorológico: uma tempestade no Atlântico Norte obrigou a frota a desviar do destino original, o Rio de Janeiro, e abrigar-se em Salvador ${ }^{5}$. Orientado pelo médico brasileiro José Corrêa Picanço, professor em Coimbra, Dom João VI criou nestas duas cidades escolas de Anatomia, Medicina e Cirurgia, que a partir de 1832 seriam elevadas à condição de Faculdades de Medicina ${ }^{6}$.

Em "A Faculdade de Medicina da Bahia na Visão de seus Memorialistas 1854-1924", Marcos Ribeiro ${ }^{5}$ apresenta um perfil de como era a escola de medicina baiana, no período em que Camilo iniciava sua vida acadêmica, pela revisão das chamadas "Memórias Históricas", as quais eram escritas anualmente por membros de seu corpo docente, desfazendo qualquer visão demasiadamente ufanística. A lei previa na época, por exemplo, que o estudante, após o ensino médio, realizasse exames preparatórios para entrar nas faculdades, em um ensaio do que chamaríamos, anos depois, de vestibular. Os exames preparatórios para medicina eram em Português, Latim, Francês, Inglês, Alemão, Filosofia, Geografia, Aritmética, Álgebra, Trigonometria Retilínea, Elementos de Física, Química e História Natural ${ }^{7}$. Com estes exames esperava-se elevar o critério de seleção. De fato as reprovações eram muitas, mas havia as denúncias do chamado "filhotismo e patronato" e das famosas "cartas de empenho", apresentadas aos examinadores no intuito de favorecerem certos candidatos ${ }^{5}$.

Ao ingressar na Faculdade do Terreiro de Jesus (Figura 1), como também era conhecida pela sua localização em pleno Pelourinho, no centro de Salvador, Camilo deparou-se com uma faculdade cujo prédio era assim definido por Anselmo da Fonseca ${ }^{8}$, memorialista de 1891:

Um edifício collocado n'um sítio pouco espaçoso, nimiamente acanhado e sem a possibilidade de ser augmentado, salvo á custa de dispendiosas desapropriações e demolições previas; que não tem as dimensões necessarias para aquartelar os dezesseis laboratorios que devem funcionar em compartimentos distinctos, diversos amphitheatros, uma enorme bibliotheca e um museu; um edificio composto de duas secções que se unem formando um angulo reintrante [...] um edificio cuja archictetura é litteralmente monstruosa, pois que se deram uns ares de modernidade e elegancia ao velho convento, cuja construção pesada e cuja forma obsoleta, foi necessario conservar e seguir na secção nova; [...] finalmente um edifício interiormente mal dividido, desproporcionado e cujo soalho se acha em níveis diferentes.

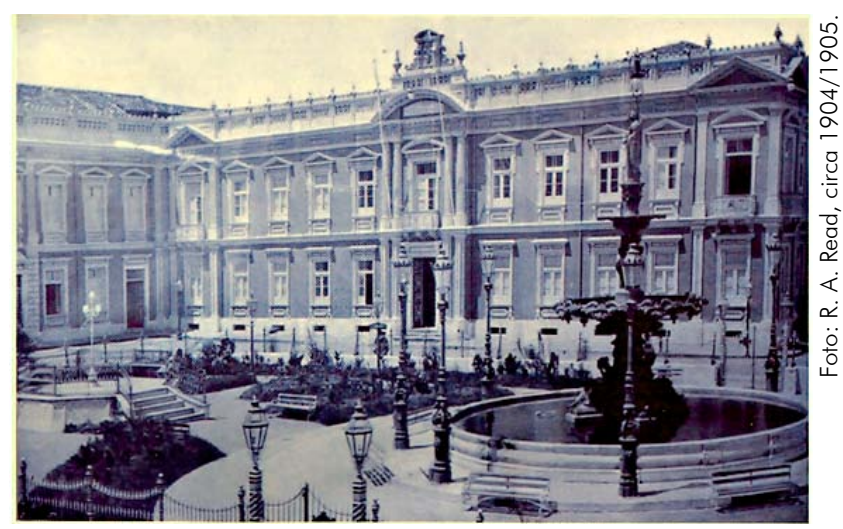

Fonte: Gazeta Médica da Bahia9.

Figura 1 - Faculdade de Medicina da Bahia, Largo do Terreiro de Jesus, Salvador, Estado da Bahia

Hospital de Caridade $^{8}$, localizado atrás da Faculdade e nos fundos dos quintais das casas da Rua das Portas, também não apresentava uma descrição muito animadora, sendo considerado um labirinto inteligível, uma

[...] disparatada agglomeração de baixos corredores, de trevosas galerias inferiores ao nivel commum do solo, d'aquelle tristonho conjuncto de grutas, de fojos, alveolos e cubículos, d'aquella sombria estancia de ar estagnado, d'aquelle insanável foco de infecção, d'aquelle monumento de barbaria, d'aquillo só uma cousa unica póde ser aproveitada: - é a área, - depois de inteiramente desoccupada pela demolição completa e pela remoção do material e de estar por muito tempo esposta á acção purificadora dos agentes naturais.

Os próprios materiais de sua demolição irremissível nós não sabemos se deverão ser de novo utilizados n'uma epocha em que, na Europa, que nos serve de guia, não sómente se apura muito a qualidade dos materiaes empregados nas construcções, como previamente se os desinfecta, quando isto é julgado conveniente.

A hygiene nunca será uma realidade pratica na vida da sociedade emquanto dos medicos e das escholas de medicina não partir o exemplo da fiel observancia de suas prescripções.

\footnotetext{
* Leandro Malthus ${ }^{4}$ divide assim as matérias por anos:

$1^{\circ}$ ano - Física, Química Mineral, Botânica e Zoologia.

$2^{\circ}$ ano - Anatomia Descritiva, Histologia e Química Orgânica e Biológica.

$3^{\circ}$ ano - Fisiologia, Anatomia Patológica, Patologia Geral e Clínica Cirúrgica.

$4^{\circ}$ ano - Patologia Interna, Patologia Externa, Terapêutica, Clínicas Interna e Externa compreendendo moléstias da pele.

$5^{\circ}$ ano - Anatomia Topográfica, Operações e Aparelhos, Obstetrícia, Clínica Interna, Externa e Oftalmológica.

$6^{\circ}$ ano - Higiene e História da Medicina, Farmacologia e Arte de Formular, Medicina Legal e Toxicologia, Clínica de Partos e outras.
} 
As instalações cirúrgicas eram definidas como "vergonhosas", a tal ponto que durante a visita de um médico estrangeiro ao hospital da Faculdade, o professor que o acompanhava sentiu-se obrigado a mentir para salvar as aparências, informando ao visitante que a sala de operações tinha sido vítima de um incêndio recente, razão pela qual as operações estavam sendo realizadas em condições provisórias em uma simples sala de curativos, conforme cita o memorialista Alfredo Britto apud Ribeiro 5 .

A biblioteca, em 1891, possuía 9.875 livros, a maioria obras francesas, e não dispunha sequer de todas as obras de seus professores e nem a coleção completa da Gazeta Médica da Bahia, publicada por aquela instituição. $\bigcirc$ memorialista daquele ano, Luiz Anselmo da Fonseca, prefere chamá-la de "depósito de livros" considerando que a mesma funcionava em uma sala comprida e estreita como um corredor, acanhada e mal arejada. Para simples comparação, a Faculdade de Medicina de Estrasburgo dispunha de 33.000 volumes e a de Viena $770.000^{5,8}$.

Se o espaço físico não era descrito de forma animadora, o ensino também era objeto de críticas dos professores, que consideravam a faculdade excessivamente teórica, onde os dons oratórios de um lente, sua eloquência e sua retórica eram muitas vezes mais valorizados que aulas práticas - quase inexistentes - e que fomentassem a investigação de uma medicina experimental. A exposição dos conteúdos era impregnada de teologia, metafísica e sentimentalismo em detrimento à objetividade e a demonstrações. Microscopia, por exemplo, em 1891, era uma recém-introduzida novidade ${ }^{5}$.

Esta era uma tendência geral durante o período enfocado, ainda que tal modelo baseado em dialética e eloquência fosse considerado decadente em boa parte da Europa, e até mesmo na França, a grande influência intelectual e científica da faculdade baiana. Esta assimilação de doutrinas francesas, sem questionamentos, sem adaptações à realidade brasileira também era objeto de críticas de professores que naquela última década do século XIX já começavam a se sentir influenciados por outras escolas, como Berlim e Viena, onde se ensinava uma medicina mais moderna $^{5}$.

Além das más condições físicas, do ensino baseado em doutrinas ultrapassadas, que começavam a ser questionadas, mas ainda impregnavam as salas de aula, outro fator era considerado prejudicial ao ensino: os baixos salários dos professores, que segundo Alfredo Britto os condenava em sua maioria a um estado de esterilidade forçada que se perpetuava por gerações ${ }^{5}$.
Independente de qualquer fator negativo, a faculdade era o centro da vida cultural e científica de toda a sociedade baiana de então, ponto de convergência dos mais diversos interesses intelectuais e profissionais, procurada por jovens que desejavam um curso superior, mas não tinham condições de estudar fora do País. Deste modo, por ser única, constituía-se em um foco de discussões de temas que hoje estariam situados nos campos da Filosofia, Antropologia, Química, Direito, Física, Biologia e Psicologia, gerando polêmicas que chegavam até os jornais e eram acompanhadas com avidez pela sociedade local ${ }^{5}$. No fim, aprendia-se um pouco de tudo, e com dedicação, até medicina.

Em 1894, Camilo encerrou sua vida acadêmica na Bahia e transferiu-se para o Rio de Janeiro no ano seguinte ${ }^{10}$. Não é difícil especular que o jovem acadêmico talvez estivesse buscando a melhor formação possível em sua futura profissão. De fato, a Faculdade de Medicina do Rio de Janeiro sempre foi privilegiada pelo poder público em relação à sua irmã nordestina, e como se não bastasse ainda acusava esta última de baixo nível científico, da falta de rigor e seriedade nos seus exames ${ }^{5}$.

maior recebimento de recursos na Faculdade de Medicina do Rio de Janeiro era sempre explicado por conta de seus maiores gastos decorrentes de seu maior número de alunos. Isso acabava repercutindo em um melhor aparelhamento da escola. Mesmo os professores da Bahia reconheciam que o Rio de Janeiro estava mais bem preparado para o ensino médico prático, com direito a investigações científicas. No Rio de Janeiro, um professor dispunha de uma enfermaria inteira com 39 leitos, na Bahia eram apenas dez ou 12 leitos, não raro ocupados por doentes crônicos, sem grande importância didática ${ }^{5}$.

Outro fator que não pode ser desconsiderado e que explica bem a situação mais favorável da Faculdade de Medicina do Rio de Janeiro é que ela estava situada na capital do Império e, depois, da República; mais perto do centro do poder, tinha acesso mais fácil a recursos financeiros ${ }^{5}$. O Imperador Dom Pedro II, por exemplo, fazia questão de comparecer a todas as solenidades realizadas na Faculdade como as colações de grau e os concursos por ela promovidos ${ }^{11}$. Esta proximidade com o poder fica patente quando observamos que a faculdade carioca tinha entre seus docentes muitos titulares do Império, barões, condes e viscondes, enquanto no mesmo período a escola baiana só possuiu um professor com título de nobreza, o Barão de Itapoa $^{12}$. A título de curiosidade histórica, apenas três faculdades de medicina do Brasil possuíram titulares do Império entre seus docentes: Rio de Janeiro, Bahia e, já em plena República, a Faculdade de Medicina e Cirurgia do Pará com o Barão de Anajás ${ }^{\dagger}$.

\footnotetext{
† Antonino Emiliano de Sousa Castro (1847-1929), médico paraense formado no Rio em 1872, agraciado com o título de Barão de Anajás em $1888^{13}$. Figura de destaque no meio médico paraense do final do segundo reinado até as primeiras décadas da República, fundador da Sociedade Médico-Farmacêutica do Pará, da Sociedade de Medicina e Cirurgia do Pará, primeiro presidente eleito da Sociedade Médico Cirúrgica do Pará, e primeiro diretor da Faculdade de Medicina e Cirurgia do Pará ${ }^{14}$.
} 
Apesar de tudo isso, o ensino médico na então capital do País também estava aquém do ideal. Quando se escreve sobre a antiga Faculdade de Medicina do Rio de Janeiro, a ideia que vem à mente é a do majestoso prédio da Faculdade Nacional de Medicina, localizado na Praia Vermelha, anos depois absurdamente demolido. No tempo em que Camilo Salgado era um estudante de medicina, esta construção não existia nem no papel, pois seria inaugurada apenas em 191911. A faculdade funcionava desde 1856 em um prédio na rua Santa Luzia, ao lado da Santa Casa (Figura 2), que havia servido como recolhimento das órfãs e por este nome era conhecido ${ }^{11}$. Fora a grande vantagem de funcionar junto do hospital, o prédio não havia sido construído para receber uma instituição de ensino médico. Pouco mais de três lustros antes da entrada de Camilo, um estudante ${ }^{4, \neq}$ assim o definiu em 1879:

Quem ha cinco annos, passasse pelo modesto Largo da Misericordia, voltando para a rua de Santa Luzia e olhasse o edificio acinzentado da esquina que fica á direita, ver-se-hia em bons embaraços se quizesse saber que casa era aquella a guiar-se pelo aspecto que apresentava. Ella tinha os modos de um velho convento demasiadamente batido e gasto pelas invectivas do tempo. A porta principal, baixa, com vão escuro e profundo, olhada a certa distancia, pintava-se na retina do mais despretencioso observador, tal qual a abertura de um tunnel. [...]

A certas horas do dia, uma porta ao lado abria-se e entravam, então, suspensos das mãos de uns homens, que tinham as vestes salpicadas de sangue, uns caixões sordidamente pintados pela immundicie [...]

Muitas vezes alguns curiosos paravam na calçada e mal equilibrados nas pontas dos pés apinhavam-se em torno da janella, apoiando-se uns nos hombros dos outros [...] e viam lá dentro mesas cobertas de cadáveres multipartidos e muita gente a fumar com escapellos na mão. [...]

Seguindo mais para dentro, via-se apparecer sem ordem nem gosto, diversas salas sotopostas umas das outras, onde os miasmas reinavam com ostentação e o ar e a luz não tinham porta franca. [...]

A Biblioteca, pouco clara, de exiguas proporções, como que engasgada entre outras salas, era antes propria para o refugio do sonno e do cançaço, que para o retiro do trabalho e do estudo ${ }^{4}$.

Camilo teve mais sorte, pois quando chegou ao Rio de Janeiro, na última década do século XIX, a Faculdade já havia tido como diretor Vicente Cândido Figueiredo de Sabóia, o Visconde de Sabóia, que de 1881 até 1889 foi o responsável por uma remodelação completa no ensino, nos costumes, nas instalações, de modo que, segundo Fernando Magalhães ${ }^{16}$, todo o renome da instituição não dependeu dos seus anos prévios, mesmo tendo contado com grandes nomes, mas sim deste período de oito anos "[...] dentro do qual a grande força de Sabóia, força moral e física, implantou entre professores e alunos o regime de disciplina e trabalho"16.

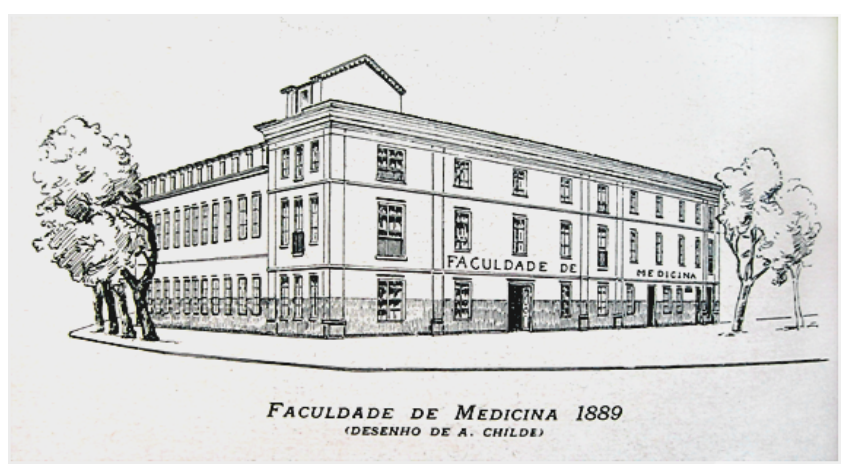

Fonte: Magalhães ${ }^{16}$

Figura 2 - Faculdade de Medicina do Rio de Janeiro

Como bem diz o ditado "não há mal que sempre dure, nem bem que nunca se acabe", com a queda da Monarquia, caiu junto o Visconde de Sabóia. A República não o manteve em seu lugar, mas não teve como não reconhecer seus méritos dando-lhe o título de "Diretor Honorário", fato jamais repetido na história da Faculdade de Medicina do Rio de Janeiro ${ }^{16}$.

Sem seu grande timoneiro, a primeira década republicana, última do século XIX, marcou um período de estagnação da Faculdade. Com a carência de recursos públicos começou também a aflorar as discordâncias entre alunos e lentes e entre os próprios mestres. $\bigcirc$ interesse entre os estudantes diminuiu e a faculdade que contava em 1882 com 1.590 alunos matriculados tinha, em 1894, pouco mais de $500^{6}$.

Camilo Salgado desembarcou no Rio de Janeiro exatamente neste contexto; se por um lado não vivenciou uma faculdade decadente como a descrita em 1879, também não viveu o apogeu da era do Visconde de Sabóia. Ainda assim, mesmo sendo definida no período como uma escola estagnada, Camilo certamente respirou os ares das reformas implementadas nos anos de 1880. A queda do número de alunos matriculados também teve seu lado vantajoso, pois foi graças a ela que se abriram vagas e Camilo Salgado pôde migrar da Bahia para o Rio de Janeiro.

Este fluxo de alunos da Bahia para a capital federal era objeto de críticas de professores cariocas, que achavam que os alunos da Bahia faziam seu curso aos saltos, com exames facilitados, e depois vinham à capital do Brasil em busca da diferença de prestígio

\footnotetext{
¥ Segundo Maia ${ }^{15}$, Leandro Malthus provavelmente é um pseudônimo, pois pesquisas realizadas não encontraram nenhum aluno com este nome na época. A hipótese é bem viável considerando que seu livro tece duras críticas à Faculdade de Medicina do Rio de Janeiro. A título de curiosidade, os autores possuem o livro de Leandro Malthus e acima deste nome um antigo dono escreveu entre parênteses Manoel Antônio Affonso dos Reis. Seria este o nome do verdadeiro autor? (N.A.)
} 
que favorecia a Faculdade de Medicina do Rio de Janeiro. Ressalte-se que o caminho inverso também acontecia: muitos estudantes de medicina, fugindo da severidade dos exames da faculdade carioca, no sexto ano médico acabavam indo parar em Salvador. Ribeiro ${ }^{5}$ cita o memorialista da escola carioca, Souza Lima, que anedoticamente assim definiu a situação:

\begin{abstract}
De mais, lá está a nossa irmã da Bahia, cheia de generosidade, para recebê-los de braços abertos, como porto de socorro aos náufragos, como amparo e refúgio dos penitentes, como tribunal de apelação sempre pronto ao indulto, e para o qual recorreriam imediatamente as inculcadas vítimas, certas de alcançarem o prêmio de sua viagem.
\end{abstract}

O cenário das aulas práticas - a Santa Casa do Rio de Janeiro -, também tinha suas mazelas, sendo definido como um hospital com enfermarias escuras e tristes e outras alegres e arejadas, estas felizmente correspondendo a maioria das instalações. A superlotação já era um problema em diversos aspectos, uma vez que a capacidade de cada enfermaria era de 32 a 36 leitos, porém era comum ver enfermarias com 40 pacientes, os excedentes acomodados no chão, entre dois leitos. Em pequenas salas anexas às enfermarias espremiam-se 60 a 100 alunos, em três ou quatro bancos compridos de madeira, para ouvir as explicações do professor. Eram realizadas ainda as chamadas "visitas", nas quais os professores passavam em cada leito, para discutir os casos, ocasião em que os estudantes se apinhavam entre o professor e o doente ${ }^{4}$.

As provas eram tidas como rigorosas, dependendo, é claro, do professor; mesmo assim, sempre existiam aqueles estudantes que davam um jeito de facilitar as coisas com a ajuda dos bedéis. Sobre o "modus operandi" destes funcionários nos dias de exames, assim recorda Malthus ${ }^{4}$ :

Durante os exames escriptos, alguns tomam posições caracteristicamente tragico-comicas. Uns- revestem se de uma imponencia atterradora e ameaçam os freguezos da colla que d'esta vez darão parte aos examinadores se virem qualquer cousa. Os estudantes já sabem e então com qualquer quantiazinha, que elles recebem com manifesta contrariedade, desmancham aquelle apparato tragico e os traços comicos tornam-se então patentes nas physionomias agradecidas. Outros... fazem o mesmo, para variar.

Tal qual na Bahia, os estudantes de medicina agitavam a vida da cidade do Rio de Janeiro; após as aulas, a crônica da época descreve bandos de acadêmicos seguindo pela tortuosa rua da Misericórdia, em direção à rua do Carmo e à rua do Ouvidor, sempre brincalhões, muito traquinas e endiabrados fazendo gracejos com os moradores. Os que não se dispersavam iam tomar um café na esquina das Cancellas onde "[...] rodeiam as mezas de marmore, assentados e conversando e, minutos depois, levantam-se saccudindo o assucar das calças, com um cigarro na bocca e um café no estomago"4.

Aqueles que não seguiam para casa para estudar, ou que ainda tinham algum dinheiro no bolso, faziam uma escala no "Taco de Ouro" ou no "Bilhar do Silva", na Travessa São Francisco de Paula. Outros seguiam descendo e subindo a rua até parar, de pé, na esquina das ruas Gonçalves Dias com Uruguaiana admirando as jovens que ali ficavam esperando os bondes até que "[...] tira-se o relogio do bolso, e toca-se para caza com a imaginação cheia do que se viu na rua e a memoria esquecida do que se ouviu na sala"4.

Foi neste contexto que Camilo Salgado fez sua graduação. Se havia dificuldades, estas tiveram como contrapeso os bons professores que o jovem acadêmico encontrou ao longo de sua jornada. Estes mestres, sem dúvida, provaram que é possível ensinar medicina adequadamente, mesmo contando com uma infraestrutura aquém do desejado. Tal percepção, anos depois, deve ter-lhe dado a segurança e a ousadia necessárias para enfrentar o desafio de criar a Faculdade de Medicina e Cirurgia do Pará.

Na Bahia, o jovem acadêmico deparou-se com nomes como Amâncio J. Cardoso de Andrade (Botânica e Zoologia), Alexandre Afonso de Carvalho, José Carneiro de Campos (ambos de Anatomia descritiva), Luis Anselmo da Fonseca (Física Médica) e ainda que não tenha chegado a cursar a disciplina Medicina Legal durante seus dias em Salvador, é impossível que não tenha recebido alguma influência de um dos maiores nomes da medicina brasileira, que ali lecionava então: Raimundo Nina Rodrigues ${ }^{12}$. Já no Rio de Janeiro, outros nomes notáveis foram agregados à formação de Camilo Salgado como Luiz da Cunha Feijó Junior (Obstetrícia), Agostinho de Souza Lima (Medicina Legal), Francisco de Castro (Propedêutica), João Pizarro (Clínica Dermatológica), Hilário Soares Gouveia (Clínica Oftalmológica), Cândido Barata Ribeiro (Clínica Pediátrica) para citar alguns ${ }^{17}$.

Com a aproximação do fim do curso era comum que os estudantes procurassem realizar um internato, que até então era uma atividade facultativa e de escolha do aluno. Só décadas depois passou a existir como uma atividade obrigatória nos currículos das faculdades de medicina. Cada um, então, procurava um serviço que mais the agradasse e pleiteava o lugar de interno, aceitando fazê-lo sem nenhuma remuneração. $\bigcirc$ simples fato de estar ligado a um determinado serviço era motivo de orgulho e enriquecimento do currículo. Alguns serviços eram tão rigorosos que ainda cobravam multas por qualquer falha ou faltas dos acadêmicos. Mas ninguém era obrigado a ser interno, existindo estudantes que se formavam sem nunca terem frequentado um serviço de clínica ou de cirurgia ${ }^{11}$. Para a maioria dos alunos, 
no último ano, as cadeiras do curso passavam a ser secundárias; com uma frequência bastante liberal, o principal era exercitar a prática ${ }^{11}$.

Camilo Salgado, junto com Raimundo Olegário da Costa, foi interno-acadêmico do Hospital São João Batista, em Niterói, Estado do Rio de Janeiro, que contava com os seguintes médicos: Manuel Pereira da Silva Continentino (diretor), Antônio Domingues de Sá (cirurgião), Eloy Benedicto Ottoni (psiquiatra), Pedro de Albuquerque Rodrigues (oftalmologista), Antônio Augusto Ferreira da Silva (obstetra), Plínio Freitas Travassos e Joaquim da Silva Nazareth (clínicos) ${ }^{18}$.

De acordo com a legislação vigente, o concluinte do curso médico era obrigado a apresentar e defender uma tese, as chamadas "Theses de Doutoramento ou Inaugurais", cujos objetivos eram fomentar a criação de uma literatura médica nacional e proporcionar ao estudante uma oportunidade de demonstrar os conhecimentos adquiridos 5 . Tal medida, implantada em 1832, no final do século XIX já era objeto de críticas com a alegação que as teses eram escritas às pressas, copiadas umas das outras, ou eram somente resumos de trabalhos estrangeiros carecendo de originalidade, formando um mero catálogo de opiniões, que ficava depois abandonado na biblioteca da Faculdade ${ }^{5,8}$. Apesar de tudo isso, publicadas em forma de livro, as teses chegavam a circular fora do meio acadêmico, sendo lidas pela elite culta interessada em novidades ${ }^{5}$.

Além da dissertação propriamente dita, as teses contavam também com três proposições sobre cada cadeira do curso e seis aforismos médicos, tirados das obras de Hipócrates ou algum tratado clássico. Para que a tese fosse defendida até o fim do ano, o aluno tinha que apresentar o manuscrito até o mês de agosto, - qual era avaliado por um lente e dois adjuntos nomeados pela congregação, que verificavam se 0 trabalho estava conforme os estatutos e não continha nenhum termo inconveniente ou desrespeitoso. Feita esta aprovação prévia, a tese era impressa, às custas do autor, em um formato pré-determinado pela faculdade devendo ser enviados 36 exemplares a esta ${ }^{3}$.

No dia da defesa, uma comissão de cinco professores indicada pelo diretor e aceita em votação simbólica pela congregação, fazia a arguição do trabalho, previamente recebido para leitura com um tempo mínimo de oito dias de antecedência. As perguntas começavam do professor mais novo, até o mais antigo. Cada um dispunha de um tempo máximo de 20 minutos conferidos por uma ampulheta ${ }^{3}$.

Encerrada a defesa, o doutorando e quem mais estivesse assistindo era convidado a deixar a sala, as portas eram fechadas e a comissão julgadora dava seu parecer. Caso o trabalho fosse reprovado, o doutorando só poderia realizar nova defesa após um prazo de três meses até um ano, a ser definido pela congregação. Se o trabalho fosse aprovado, antes da colação de grau o autor tinha que entregar 100 exemplares impressos da tese à secretaria da Faculdade, os quais seriam distribuídos entre os professores, alguns enviados ao governo e a outra Faculdade de Medicina. $\bigcirc$ restante ficava arquivado na biblioteca ${ }^{3}$.

Camilo defendeu sua tese em 20 de outubro de 1896, cujo título foi "Influência da metrite sobre a gestação", sendo a mesma aprovada plenamente, o que significa dizer que não foi aprovada com distinção, o grau máximo que uma tese poderia receber.

Avaliando o trabalho de Camilo em seu contexto histórico, observa-se que ele segue o padrão de teses daquele período. Longe de buscar um ponto de vista nacional ou trazer inovações, pois as faculdades não tinham preparo para ensinar ou incentivar estudos em medicina experimental, o valor da tese estava na capacidade de sintetizar opiniões diversas sobre um tema fazendo o que atualmente se denomina de "revisão da literatura". Em um tempo em que as revistas médicas eram escassas e os livros de acesso restrito, a grande maioria em outros idiomas, a tese de Camilo Salgado, como as demais daquela época, cumpria seu papel de tornar as atualizações médicas mais acessíveis para os leitores da língua portuguesa.

Após a defesa de tese, o último ritual era a colação de grau. Segundo o seu diploma, Camilo colou grau em 5 de fevereiro de 1897 (Figura 3) em uma cerimônia na época assim descrita: cada candidato vestido em trajes "doutoraes" chegava à porta principal do edifício da Faculdade, onde era recebido pelos bedéis e contínuos, que o acompanhavam até a sala onde ocorreria a colação. Ali, o concluinte aguardava com outros doutorandos o início da cerimônia. Na sala de colação de grau havia uma cadeira de espaldar para o diretor e ao seu lado direito duas cadeiras, uma para um professor escolhido pela turma, o paraninfo, na época simplesmente denominado de "padrinho", e a outra para o orador, que tal como hoje era um concluinte escolhido entre seus colegas. $\mathrm{Na}$ mesma sala, além de bancos e cadeiras para os estudantes, havia lugares especiais para os lentes, para altos funcionários públicos e demais convidados especiais $^{3}$.

Depois que todos tivessem tomado assento, o Secretário fazia a leitura do termo de aprovação. Em seguida, os doutorandos eram chamados um a um para fazerem o juramento e colar grau. $\bigcirc$ primeiro prestava o juramento por extenso e os demais apenas repetiam a fórmula: "Assim o juro". A fórmula de juramento vale ser transcrita, pois é diferente da atual: 


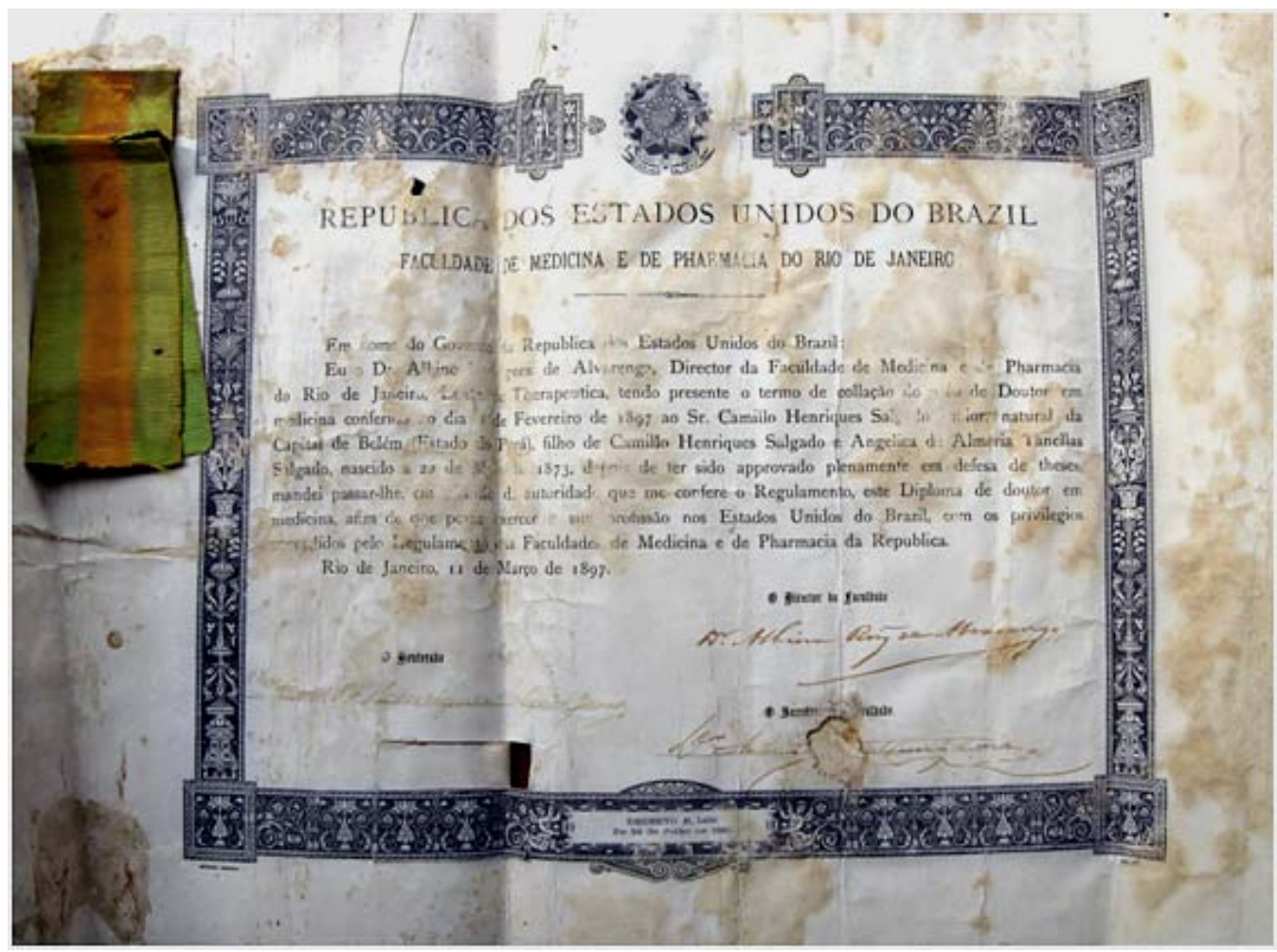

Figura 3 - Diploma de Doutor em Medicina obtido por Camilo Salgado

Fonte: Acervo Ubirajara Salgado.

\begin{abstract}
O doutorando, de joelhos, põe a mão sobre um livro dos Santos Evangelhos e profere o seguinte juramento:

"Juro aos Santos Evangelhos que no exercicio da medicina serei sempre fiel aos deveres da honra, da sciencia e da caridade".

O doutorando levanta-se, e, pondo a mão sobre as obras de Hippocrates, continúa:

"Prometto sobre as obras de Hippocrates que, penetrando no interior das famílias, meus olhos serão cegos, e minha lingua calará os segredos que me forem confiados; nunca de minha profissão me servirei para corromper os costumes nem para favorecer o crime".

Director entrega ao candidato um exemplar das obras de Hippocrates dizendo:

"Lêde e meditai sobre as obras do pai da medicina. Regule-se a vossa vida pela delle, e os homens cobrirão de bençãos o vosso nome".

Pondo o anel no dedo do doutorando, dizia-lhe:

"Recebei este annel como symbolo do gráo que vos confiro. Podeis praticar e ensinar a medicina".

Em seguida abraça o novo doutor ${ }^{3}$.
\end{abstract}

Preenchidas as formalidades da colação de grau, o orador era chamado para ler seu discurso, que já havia sido previamente apresentado e aprovado pelo Diretor, que somente o liberava se fosse julgado conveniente. A seguir era a vez do "padrinho" da turma fazer o uso da palavra congratulando-se com os novos doutores pelo resultado de seus esforços. Terminados os discursos, o Diretor dava por encerrada a cerimônia e os estudantes eram acompanhados até à porta da Faculdade ${ }^{3}$. Uma última olhada no prédio, muitas lembranças, abraços e despedidas de colegas, muitos dos quais vinham dos mais diversos cantos do Brasil e jamais se encontrariam novamente após aquela data.

O acervo documental da atual Faculdade de Medicina da Universidade Federal do Rio de Janeiro está em fase de organização, não sendo possível obter, ainda, as listas exatas dos componentes das turmas daquele período. Segundo dados fornecidos pela professora Diana Maul de Carvalho, segue abaixo os nomes dos alunos que defenderam tese em 1896 e que compõem a provável turma de Camilo Salgado. A lista pode estar incompleta, iá que nem todas as teses sobreviveram à voracidade do tempo.

Foram eles: Adolph Carlos Lindenberg (posteriormente professor catedrático de Dermatologia na Faculdade de Medicina de São Paulo, com estudos sobre hanseníase, leishmaniose e pênfigo foliáceo), Alberto de Andrade Machado, Álvaro Porfírio Andrade Ramos (chegaria a membro da Academia Nacional de Medicina em 1902), Antonio Gonçalves de Araúio Penna, Antonio Pacheco Leão (anos depois diretor do Jardim Botânico do Rio de Janeiro de 1915 até 1931), Arthur Moncorvo (mais conhecido como Moncorvo Filho, pioneiro da puericultura e proteção à infância no Brasil), Augusto Cesar de Freitas, Augusto do Amaral Peixoto, Augusto Torreão Roxo (clinicou muitos anos em Belém), Carlindo Netto Valeriani, Cesar Cândido Pereira da Fonseca, Eduardo de Gusmão Lobo, Ernani Carlos de Menezes Pinto (da cadeira de Histologia 
da Faculdade de Medicina do Rio de Janeiro e da Academia Nacional de Medicina), Eurico Ernesto de Lemos, Francisco José Laraya, Franklin da Cunha Moreira, João Pedro de Albuquerque, João Rodrigues d'Almeida Basto, Jonas Correa da Costa, José Antonio de Abreu Fialho (catedrático de Oftalmologia e diretor da Faculdade de Medicina do Rio de Janeiro de 1926 até 1930), José da Silva Ferreira, José Dias Moreira, José Joaquim de Moraes Sarmento, José Luiz de Oliveira Guimarães, José Paulino de Oliveira, José Saturnino Lago, José Thomas Nabuco de Gouvêa (estudou medicina em Paris, apenas defendeu tese no Rio para revalidação de diploma, membro da Academia Nacional de Medicina desde 1904, livre docente de clínica ginecológica em 1912 na Faculdade de Medicina do Rio de Janeiro, chefiou a equipe médica brasileira enviada para França na I Guerra Mundial, embaixador do Brasil na Suíça e no Peru), Luiz Antonio Moretzsohn Barbosa, Luiz Nogueira Flores, Newton Augusto Rodrigues Campos (natural do Pará), Norberto Pereira da Fonseca, Paulino de Avelar Werneck, Raymundo Olegário da Costa (paraense, oftalmologista em Belém), Sebastião Edmundo Mariano e Silva (professor de botânica e ciências naturais da Escola Normal de Niterói), Tibúrcio Valeriano Pecegueiro do Amaral e Vicente José da Maia.

Anel de esmeralda no dedo, diploma na mão; uma vida inteira pela frente no exercício de sua profissão. Camilo Salgado deve ter sentido, naqueles dias, todas as inquietações e inseguranças que se passam na mente de qualquer recém-formado. Descortinava-se um mundo de possibilidades e também de incertezas.

Entretanto, a capital federal não seduziu o jovem doutor, e no dia 19 de fevereiro de 1897, poucos dias após a outorga do grau, ele embarcou rumo ao norte no paquete "Alagoas"19.

Após algum tempo em Belém, talvez reforçado pela precariedade do ensino médico nacional, Camilo foi buscar aprimoramento profissional em Paris, como era prática comum naquela época, tendo frequentado importantes serviços cirúrgicos até voltar definitivamente para a capital do Pará $^{10}$. Esta etapa de sua "pós-graduação" na Europa apresenta poucos relatos e possui algumas contradições ${ }^{\S}$, merecendo mais estudos para abordagens subsequentes.

Passadas pouco mais de duas décadas da formatura, a vida de Camilo Salgado ainda encontraria espaço para uma terceira escola médica, a Faculdade de Medicina e Cirurgia do Pará (Figura 4), que ele ajudou a fundar em 1919, assumindo o cargo de diretor com a renúncia do Barão de Anajás em 1922, função em que permaneceu até sua morte, 16 anos depois (Figura 5).

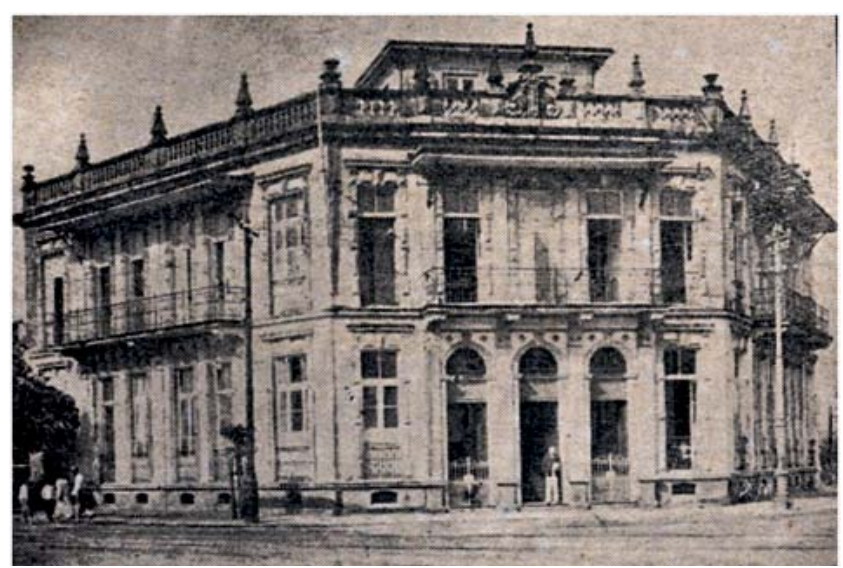

Fonte: Faculdade de Medicina do Pará21.

Figura 4 - Palacete Santa Luzia adquirido durante a direção de Camilo Salgado, mediante subscrição popular para ser a sede da Faculdade de Medicina e Cirurgia do Pará

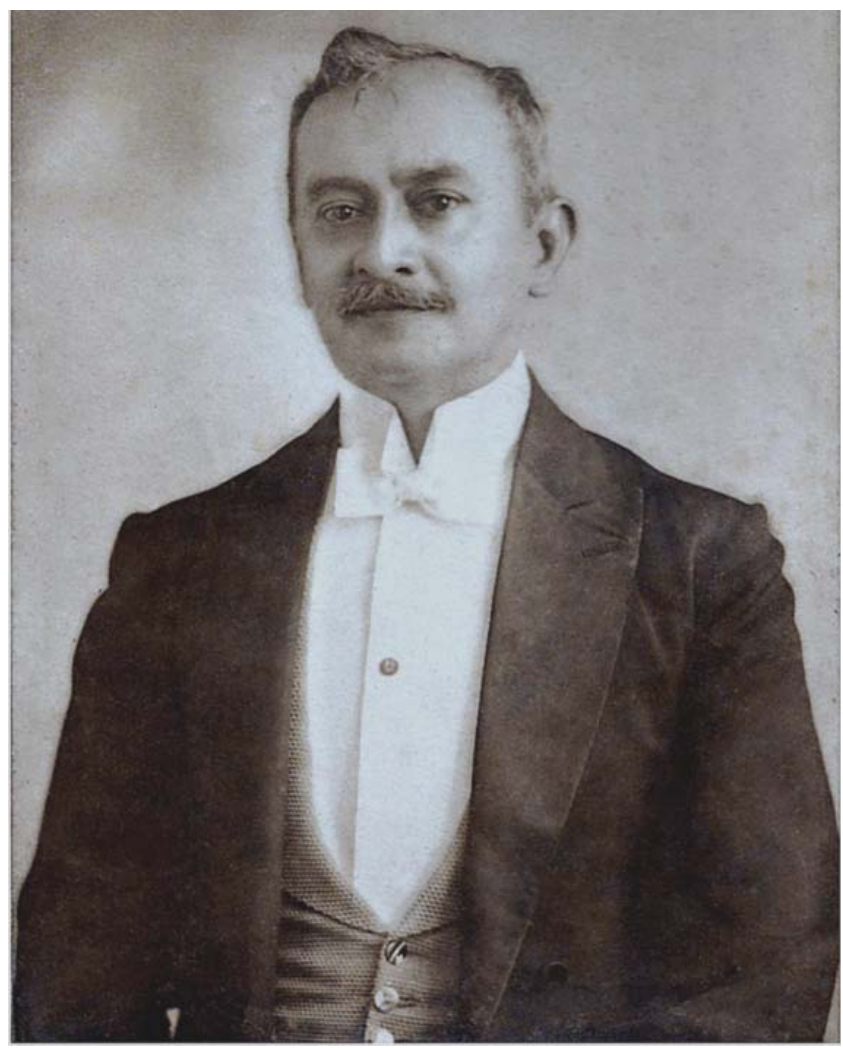

Fonte: Acervo Ubirajara Salgado.

Figura 5 - Camilo Henriques Salgado Junior na década de 1920

\section{AGRADECIMENTOS}

À prof. ${ }^{a}$ Diana Maul de Carvalho, pelos dados fornecidos sobre os alunos que defenderam tese em 1896 na Faculdade de Medicina do Rio de Janeiro, e ao prof. Ubirajara Salgado, pelas imagens do diploma e foto do dr. Camilo Salgado.

\footnotetext{
§ Por exemplo: Pantoja afirma que em sua viagem a Paris Camilo Salgado frequentou a Clínica do Prof. Charcot, chegando a viajar de trem com este de Paris até Versalhes. Jean-Martin Charcot, considerado um dos maiores nomes da medicina francesa, faleceu em 1893 quando Camilo Salgado era apenas acadêmico de medicina. Seria este Charcot então Jean-Baptist Charcot $^{20}$ médico filho do primeiro, porém mais conhecido como explorador da Antártica?
} 


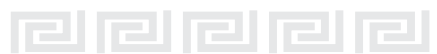

\section{Camilo Salgado and his three medical colleges}

\section{ABSTRACT}

This paper reviews medical education in Brazil during the last decade of the $19^{\text {th }}$ century in the only medical schools then in existence (Rio de Janeiro and Bahia), having as reference the academic years of Camilo Salgado, who, later, became a prominent figure in the medical history of Pará State.

Keywords: Academic Medical Centers; Medicine; History of Medicine; Medical Education; Medical Schools.

\section{Camilo Salgado y sus tres facultades de medicina}

\section{RESUMEN}

El artículo revé la formación del médico en Brasil, en la última década del siglo XIX, e las únicas escuelas médicas existentes entonces (Rio de Janeiro y Bahia) tomando como base los años académicos de Camilo Salgado, que posteriormente fue una figura de destaque en la historia de la medicina en el Estado de Pará.

Palabras clave: Centros Médicos Académicos; Medicina; Historia de la Medicina; Enseñanza Médica; Escuelas Médicas.

\section{REFERÊNCIAS}

1 Costa EM. Médico de ontem e de hoje: ciência, fé e santidade no culto a Camilo Salgado (18741938) em Belém do Pará [dissertação]. Belém (PA): Universidade Federal do Pará; 2003.

2 Camillo Salgado. O Democrata, Belém. 1891 mar $19 ; 2(63): 2$.

3 Brasil. Collecção das Leis do Imperio do Brazil de 1884: parte 2 - Atos do Poder Executivo. Rio de Janeiro: Typographia Nacional; 1885. Decreto n. 9.311, de 25 de Outubro de 1884. Dá novos estatutos ás Faculdades de Medicina; p. 478-552.

4 Malthus L. Apontamentos e commentarios sobre a Escola de Medicina Contemporanea do Rio de Janeiro. Rio de Janeiro: Lombaerts \& C; 1883.

5 Ribeiro MAP. A faculdade de medicina da Bahia na visão de seus memoralistas 1854-1924. Salvador: Universidade Federal da Bahia; 1997.

6 Gomes MM, Vargas SSM, Valladares AF. A Faculdade de Medicina Primaz do Rio de Janeiro em dois dos cinco séculos de história do Brasil. Rio de Janeiro: Atheneu; 2001.

7 Silva A. A primeira médica do Brasil. Rio de Janeiro: Irmãos Pongetii; 1954.

8 Fonseca LA. Memória histórica da Faculdade de Medicina da Bahia relativa ao anno de 1891. Salvador: Diário da Bahia; 1893.
9 Gaz Med Bahia. 2007 ago-dez;77(2):capa.

10 Pantoja SO. O desapparecimeto do Dr. Camillo Salgado. Folha do Norte, Belém. 1938 abr 28:6.

11 Maia GD. Biografia de uma faculdade: histórias e estórias da Faculdade de Medicina da Praia Vermelha. Rio de Janeiro: Atheneu; 1996.

12 Oliveira ES. Memória histórica da Faculdade de Medicina da Bahia concernente ao ano de 1942. Salvador: Centro Editorial e Didático da UFBA; 1992.

13 Miranda AG, Abreu Jr JM. Memória histórica da Faculdade de Medicina e Cirurgia do Pará, 1919/1950: da fundação a federalização. Belém: Fadesp; 2009.

14 Miranda AG. A epidemiologia das doenças infecciosas no início do século XX e a criação da Faculdade de Medicina e Cirurgia do Pará [tese]. Belém (PA): Universidade Federal do Pará, Pós-Graduação em Biologia de Agentes Infecciosos e Parasitários; 2013.

15 Maia GD. A Nacional de Medicina - 200 anos: do Morro do Castelo à llha do Fundão. Rio de Janeiro: Atheneu; 2009.

16 Magalhães F. O centenário da Faculdade de Medicina do Rio de Janeiro 1832-1932. Rio de Janeiro: Barthel; 1932.

17 Salgado $\mathrm{CH}$. Influencia da metrite sobre a gestação [tese]. Rio de Janeiro (RJ): Faculdade de Medicina e Pharmacia do Rio de Janeiro; 1896. 
18 Laemmert E, Saver A, organizadores. Almanak administrativo, mercantil e industrial do Rio de Janeiro para 1897: obra estatística e de consulta fundada em 1844, 54 $4^{\circ}$ anno. Rio de Janeiro: Companhia Typographica do Brazil; 1897.

19 Sahidas no dia 19. Gaz Noticias. $1897 \mathrm{fev}$ $20 ; 23(51): 5$.
20 Teive HAG, Munhoz RP, Simões JC. Charcot's son, commander Jean-Baptiste Charcot: from neurology to "Pourquoi Pas?". Arq Neuro-Psiquiatr. 2012 Apr;70(4):305-7.

21 Faculdade de Medicina do Pará. Trechos de relatórios apresentados à congregação. Belém: Typographia da Livraria Gillet; 1923. 